\title{
Wet granulation: the effect of shear on granule properties
}

\author{
D. Oulahna*, F. Cordier, L. Galet, J.A. Dodds \\ Ecole des Mines d'Albi-Carmaux, Laboratoire de Génie des Procédés Divisés, UMR CNRS 2392, Campus Jarlard, F81013 Albi, France \\ * Corresponding author: driss.oulahna@mines-albi.fr
}

\begin{abstract}
This paper presents a study of the wet granulation of fine cosmetic particles using a high-shear mixer granulator on a given particle and binder system. The shear effect on granule properties is highlighted. The granules formed under different impeller speeds are divided into size classes and further examined in terms of porosity, friability and binder content.

The main result of this study is that, depending on operating conditions, the granulation of a fine powder with a given binding liquid can result in the formation of granules of very different characteristics in terms of size, porosity and friability. Mechanical energy brought to the granulation system is as important as the physicochemical characteristics of the powder-binder pair.
\end{abstract}

Keywords: Wet granulation; High-shear mixer; Porosity; Friability; Binder content

\section{Introduction}

Size enlargement by wet granulation is widely used in the powder treatment industries. The wet granulation process consists of agglomerating powder particles with a binder, followed by drying to remove the solvent and obtain dry granules. The dried granules, which may be screened to provide a particle size range, can be the final product or an intermediate product for further processing, as in the formation of compacts and tablets. However, phenomena taking place in granulators are still not well understood, and it is difficult to successfully produce a product with the desired properties (size, morphology, hardness and friability) without extensive experimental tests.

It is generally recognised that increasing the binder addition rate increases the granule size and the granule bulk density due to increased penetration and wetting by the binder solution [1-3]. Despite some recent exceptions [46], the binder content or the liquid distribution in granules, which is a key parameter in granule growth, has received little attention.

Many authors $[7,8]$ have studied the evolution of granule porosity during granulation and revealed the mechanism of granule densification leading to the expulsion of binder liquid from pores inside granules to the granule surface. This phenomenon is important in granule growth mechanisms and affects the deformability of granules. The effect of binder liquid viscosity has been pointed out for some years [9], but investigations have only considered the average granule, independent of the reality of granule size distribution. Other authors $[10,11]$ have developed methods to optimise the liquid content and to control granulation process by measurement of the rheological behaviour of the wet mass during granulation.

In previous work with a pan granulator [6], we determined the granule binder content by thermogravimetry and demonstrated the great importance of the mode of incorporation of the binding liquid on granule growth and their final properties. It was shown that, for a given granulation experiment, granule properties depend on their size suggesting that it is necessary that the binder ratio and porosity distributions be taken into account in population balance models.

This paper examines the effects of shear on granule properties and on the binder content in granules. The same experimental strategy as used in Ref. [6] is applied here to the case of a high-speed mixer granulator (Diosna-6 1). In order to understand the phenomena, which govern granule formation, we have studied the influence of the operating time and impeller speed on granule quality: granule size distribution, porosity, friability, morphology and binder content of each granule size class. 


\section{Materials and methods}

\subsection{Materials}

The powder to be granulated is a surface-treated sericite (MACREPOS), generally used in the cosmetic industry. The main characteristics are summarised in Table 1.

\subsection{Liquid requirement for granulation}

Previous preliminary work on the granulation of sericite gave information on the appropriate composition of the liquid binder phase.

\subsubsection{Surface free energy approach}

Before studying granulation, the interactions between liquid and powder were characterised by the Stevens method [12]. In this, the surface energy of a powder is determined by sprinkling the powder on liquids with a range of surface tensions (i.e. various isopropanol/water solutions). The surface energy value of the powder corresponds to the surface tension of the isopropanol/water solution that begins to wet the powder. With this method, we obtained for the sericite: $\gamma=30 \mathrm{mN} / \mathrm{m}$.

In our case, the surface tension value of the binder phase $(25 \mathrm{mN} / \mathrm{m})$ is smaller than this value, so the binder phase wets perfectly the powder. Table 2 summarises the composition and the characteristics of the liquid phase.

\subsubsection{Approach using a mixer torque rheometer}

In order to predict the liquid requirement for granulation, a mixer torque rheometer (Caleva) was used to measure the variation of impeller torque as liquid was added to the powder $[10,11]$. The torque of the wet powder versus liquid to solid ratio is shown in Fig. 1. It can be seen that there is an increase in torque with increasing liquid content up to a maximum value, which is followed by a decrease as slurry is produced.

The optimum liquid, requirement for granulation, corresponds to the maximum mean torque value (capillary state). Here, it is found that an optimum binder phase/sericite couple requires an average mass ratio of $32 \%$, which corresponds to a binder (PEG 20000) to solid ratio of $5.7 \% \mathrm{w} / \mathrm{w}$.

Table 1

Powder properties

\begin{tabular}{llllll}
\hline Material & $\begin{array}{l}\text { True } \\
\text { density } \\
\left(\mathrm{g} / \mathrm{cm}^{3}\right)\end{array}$ & $\begin{array}{l}\text { B.E.T. } \\
\text { specific } \\
\text { surface } \\
\left(\mathrm{m}^{2} / \mathrm{g}\right)\end{array}$ & $\begin{array}{l}\text { Weight } \\
\text { median } \\
d_{50}(\mu \mathrm{m})\end{array}$ & $\begin{array}{l}\text { Span } \\
\left(d_{90}-d_{10}\right) /\end{array}$ & Morphology \\
$d_{50}$ & & \\
\hline $\begin{array}{l}\text { Sericite } \\
\text { (Macrepos) } \\
\text { hydrophobic- } \\
\text { cohesive }\end{array}$ & 2.67 & 8.6 & 9.2 & 2.7 & little plates \\
\hline
\end{tabular}

Table 2

Liquid phase composition and properties

\begin{tabular}{|c|c|c|c|}
\hline Material & $\begin{array}{l}\text { Liquid phase } \\
\text { composition } \\
(\% \mathrm{~W} / \mathrm{W})\end{array}$ & & \\
\hline $\begin{array}{l}\text { Binding agent: } \\
\text { polyethyleneglycol } \\
20000 \text { (Fluka) }\end{array}$ & 17.8 & & \\
\hline $\begin{array}{l}\text { Wetting agent: } \\
\text { purified water }\end{array}$ & 16.8 & & \\
\hline Ethanol (Prolabo) & 65.4 & & \\
\hline Material & Density $\left(\mathrm{g} / \mathrm{cm}^{3}\right)$ & $\begin{array}{l}\text { Surface tension } \\
(\mathrm{mN} / \mathrm{m})\end{array}$ & $\begin{array}{l}\text { Viscosity } \\
(\mathrm{mPa} s)\end{array}$ \\
\hline Liquid phase & 0.889 & 25 & 39 \\
\hline
\end{tabular}

Capes [13] has established an empirical correlation to evaluate the liquid requirement to saturate all the powder (weight liquid content $W$ ) which depends on the true solids density $\left(\rho_{\mathrm{S}}=2.67 \mathrm{~g} / \mathrm{cm}^{3}\right)$, the liquid density $\left(\rho_{\mathrm{L}}=0.889 \mathrm{~g} /\right.$ $\left.\mathrm{cm}^{3}\right)$ and porosity of the powder $(\varepsilon=0.72)$. This is based on the assumption supposed that the voids are entirely filled with the liquid phase.

$W=\frac{\varepsilon \rho_{\mathrm{L}}}{\varepsilon \rho_{\mathrm{L}}+(1-\varepsilon) \rho_{\mathrm{S}}}$

Under the conditions used here, this equation predicts a liquid to solid ratio $W=46 \%$ that is greater than the value measured with the rheometer. This can be explained by the fact that Capes did not consider the capillary effect between liquid and solid, which induces partial filling of the internal pores. Therefore, the correction done by the measurement of the torque in comparison of Capes correlation is a good estimation of the capillary state corresponding to an optimum granulation.

The question is then to verify that the binder content $(5.7 \%)$ is well dispersed in granules (see Section 1.6.4).

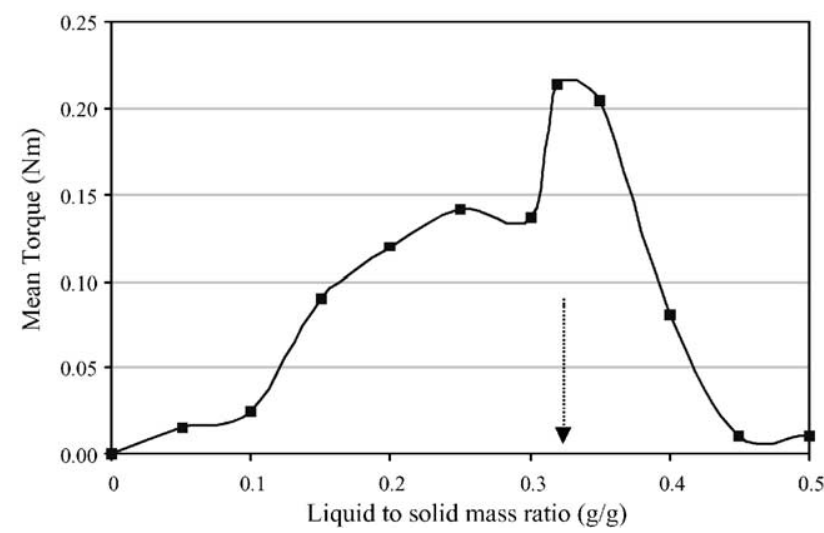

Fig. 1. Rheological profile of the wet sericite by liquid phase with the mixer torque rheometer caleva. 


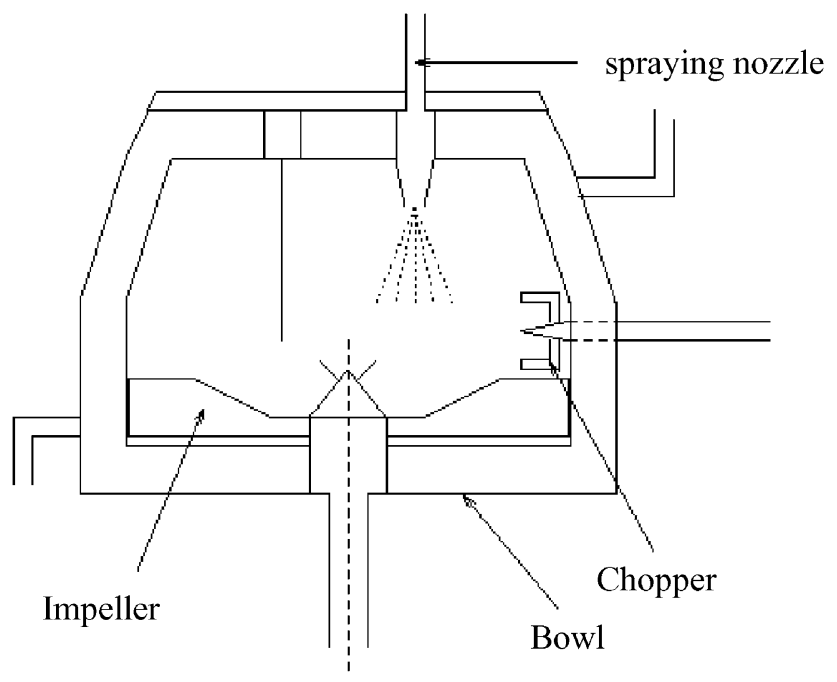

Fig. 2. Experimental set-up.

\subsection{The wet granulation process}

Batch granulations have been performed with a Diosna high-shear mixer with a horizontal bowl with a capacity of 6 1 and a spraying system (Fig. 2). The mixing shaft is a vertical axis with four plough blades. The bowl is also equipped with a chopper in a form of a tulip. A cover is placed over the bowl top to support the atomising nozzle. Spraying therefore occurs at the top of the bowl. The movement of impeller blades induces powder flow, and the binder liquid is introduced continuously on the powder bed. Size enlargement is thus brought about by the mechanical agitation action of the mixer on the wet material.

The maximum speed of the impeller is $1500 \mathrm{rpm}$. As the use of chopper was found not to influence granulation, the chopper was not used in the experiments described here. The spray system comprises a liquid feed circuit and an air feed circuit to a bi-fluid nozzle with an angle of jet dispersion of $30^{\circ}$. Under the experimental conditions used, the mean size of liquid droplets was $d_{50} \approx 80 \mu \mathrm{m}$ as determined with a laser particle size instrument (Malvern 2000).

After granulation, the granules were dried at a temperature of $60{ }^{\circ} \mathrm{C}$ for $15 \mathrm{~h}$. This temperature was chosen to allow evaporation of the wetting agent (water and ethanol) and prevent disappearance of the binder agent polyethyleneglycol (P.E.G. 20000).

Three impeller speeds were used: low, $100 \mathrm{rpm}$, medium, $500 \mathrm{rpm}$ and high, $1000 \mathrm{rpm}$, to examine the effect on the granule properties (size distribution, porosity, friability and binder content).

\subsection{Analysis techniques}

In each experiment, the size distribution of granules was obtained by sieving, and several properties of each granule size fraction were measured by various analysis techniques:

1. The porosity of dried granules was determined by a mercury porosimetry (Micromeretics).

2. The friability was determined with a standard rollingdrum apparatus (ERWEKA). The index of friability is the ratio between mass of broken granules mass and the initial granule mass after 200 rotations.

3. The binder content (binder to solid mass ratio) was determined by thermogravimetric analysis TGA (SETARAM). This consists in following the weight loss and heat flow during heating [6] when samples of granules $(40 \mathrm{mg})$ are heated under a nitrogen atmosphere from 30 to $800{ }^{\circ} \mathrm{C}$ at heating rate of $5{ }^{\circ} \mathrm{C} / \mathrm{min}$. The mass loss during heating allows the determination of the binder content of granules.

4. The morphological observation by scanning electron microscopy (Phillips XL30).

\section{Results and discussion}

\subsection{Macroscopic aspects}

Granulation experiments have been performed at different liquid to solid ratios for a number of different mixing operating conditions. A first result is the granulation profile during spraying as function of the three impeller speeds. For each speed, we measure the mass distribution of granules as a function of the liquid to solid ratios. In order to lighten the presentation, we only describe the granulation profile observed for a single series parameters. Other results are similar. The granulation parameters selected are given in Table 3.

In our study, we only consider three size fractions:

1. the fine particles whose size is less than $50 \mu \mathrm{m}$

2. the granules having size between $50 \mu \mathrm{m}$ and $4 \mathrm{~mm}$

3. the large granules whose size is larger than $4 \mathrm{~mm}$.

Fig. 3 shows the evolution of these three fractions as a function of the liquid to solid ratios (i.e. operating time as binder flow is maintained constant). As the liquid content increases, three successive tendencies are found.

1. Regime I, in which the proportion of fines particles decreases, benefiting other granule size classes. This

Table 3

Granulation parameters

\begin{tabular}{llllll}
\hline $\begin{array}{l}\text { Pulverisation } \\
\text { rate }(\mathrm{g} / \mathrm{h})\end{array}$ & $\begin{array}{l}\text { Impeller } \\
\text { speed } \\
(\mathrm{rpm})\end{array}$ & $\begin{array}{l}\text { Powder } \\
\text { mass }(\mathrm{g})\end{array}$ & $\begin{array}{l}\text { Operating } \\
\text { time }(\mathrm{min})\end{array}$ & $\begin{array}{l}\text { Liquid to } \\
\text { solid ratio } \\
(\mathrm{w} / \mathrm{w})\end{array}$ & $\begin{array}{l}\text { Chopper } \\
\text { presence }\end{array}$ \\
\hline 220 & 500 & 200 & $15-20$ & $24.8-33.5$ & no \\
\hline
\end{tabular}




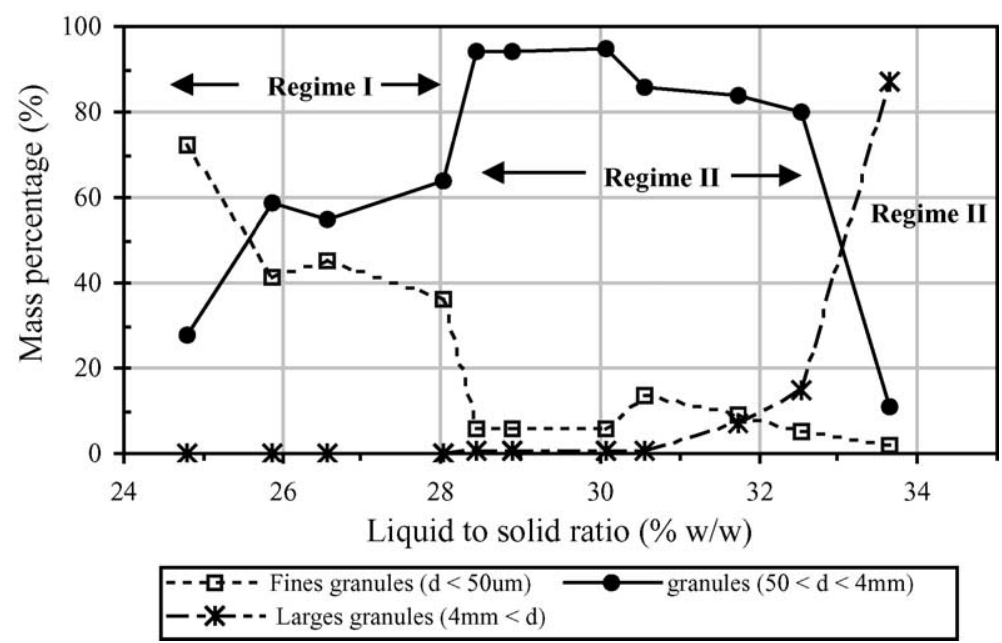

Fig. 3. Evolution of size fractions versus liquid to solid ratio $(N=500 \mathrm{rpm})$. Three regime granulation profile.

corresponds to the initiation of the granulation regime (Fig. 4).

2. Regime II, in which the proportion of granules having a size between $50 \mu \mathrm{m}$ and $4 \mu \mathrm{mm}$ is maximum and approximately constant. This is the regime of controlled granulation (Fig. 5).

3. Regime III, in which the proportion of large granules increases rapidly and there is uncontrolled granule growth, at a point close to overwetting (Fig. 6).

It is found that the general features of the three regime granulation profile do not depend on the operating conditions. However, the transition points between the different regimes do depend upon the impeller speed. Thus, if we only consider the macroscopic aspects of granulation, two important parameters emerge from these observations.

1. The liquid to solid ratio required to reach the second regime. The less this is, the less liquid is required to obtain a controlled granulation. This parameter is very important because it can lead to a reduction of granulation time and the amount of binder used.

\section{(a)}

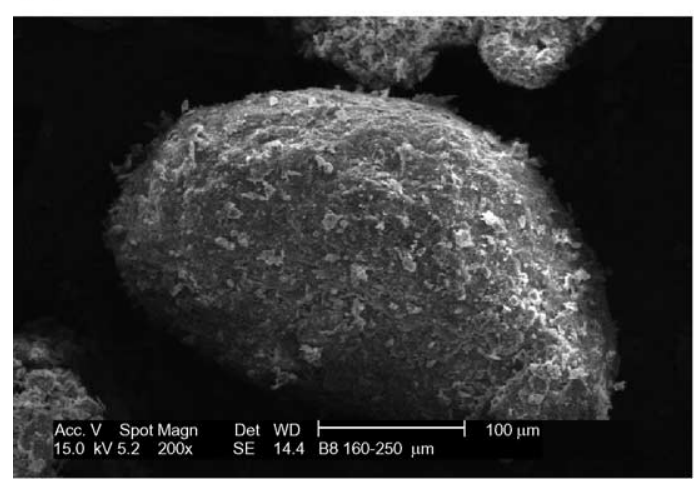

2. The extent of the second regime in terms of liquid to solid ratio. The larger this regime, the easier it is to control granulation.

The impeller speed changes the extent of the second regime and the positions of the transitions between regimes. It is found that the increase of impeller speed leads to:

1. a decrease of the proportion of fines

2. an increase in the extent of the second regime which allows a better control of the optimal point of granulation

3. a decrease of the liquid to solid ratio necessary to reach the optimum point of granulation.

To conclude, a high impeller speed is necessary to have a good control of granule growth.

\subsection{Shear effect on granule characteristics}

This section presents the influence of impeller speed on dry granule characteristics. The mass size distribution of granules, porosity, friability and binder to solid ratio per

\section{(b)}

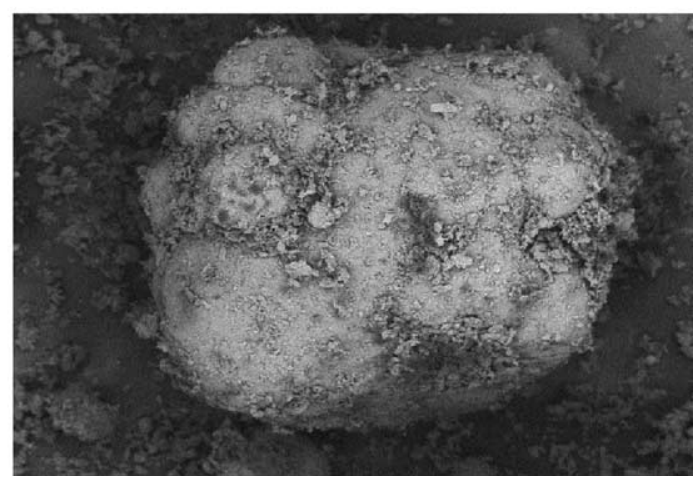

Fig. 4. $(\mathrm{a}-\mathrm{b})$ Nucleation, coating and coalescence between nuclei (Regime I), size class $(160-250 \mu \mathrm{m}), \mathrm{L} / \mathrm{S}=31.7 \%$, top $=19 \mathrm{~min}, N=500 \mathrm{rpm}$. 
(a)

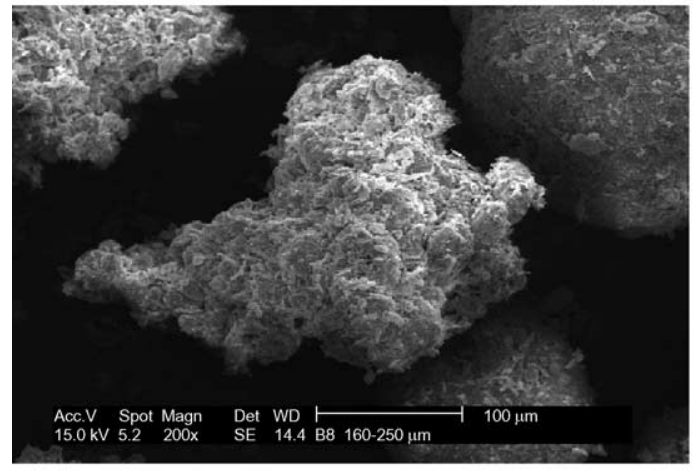

(c)

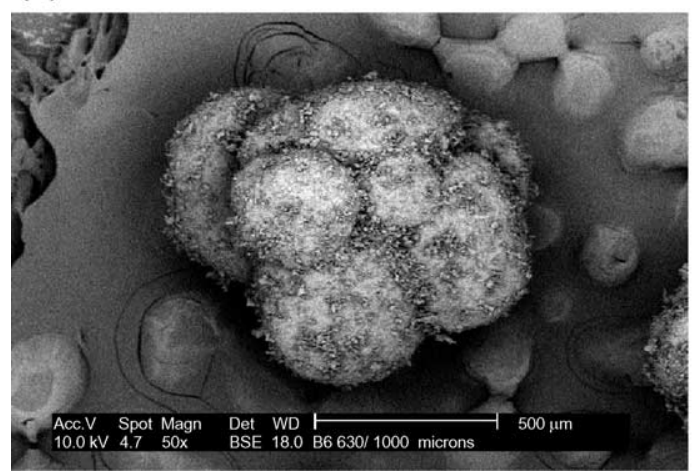

(b)

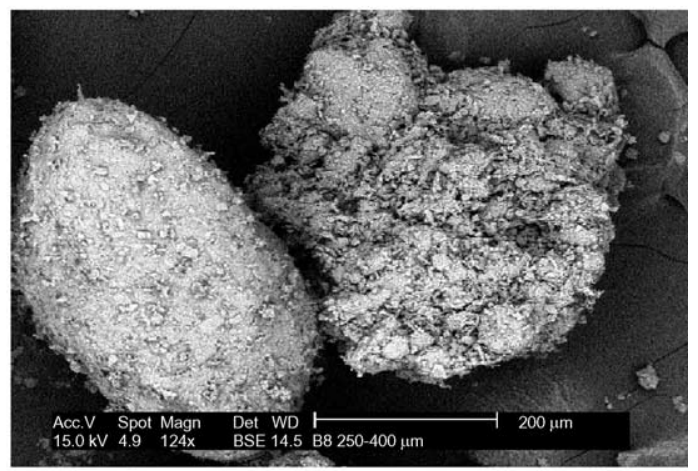

(d)

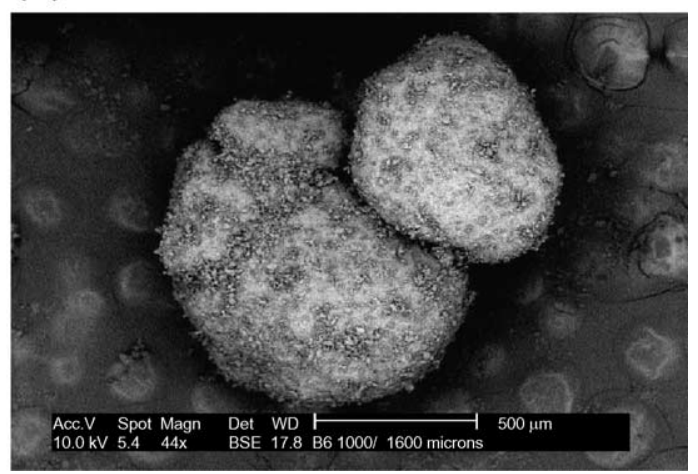

Fig. 5. (a-b) Densification (Regime II), small granules $(160-400 \mu \mathrm{m}), \mathrm{L} / \mathrm{S}=31.7 \%$, top $=19 \mathrm{~min}, N=500 \mathrm{rpm}$. (c-d) Coalescence (Regime II), granules $(630-1600 \mu \mathrm{m}), \mathrm{L} / \mathrm{S}=31.7 \%$, top $=19 \mathrm{~min}, N=500 \mathrm{rpm}$.

size fraction have been studied under different mixing conditions. In effect, we observe a complete similarity whatever the liquid to solid ratio is. Thus, in order to lighten this presentation, we only describe the granule characteristics for a single operating time. Other results are similar. The granulation parameters selected are given in Table 4.

\subsubsection{Influence of shear on mass size distribution of granules}

The influence of the impeller speed (100, 500 and 1000 $\mathrm{rpm})$ on the size distribution of granules was investigated (Fig. 7). As observed above, low-shear granulation (100 rpm) leads to more fine particles and a wider size distribution. This can be explained by the fact that the binder liquid (a)

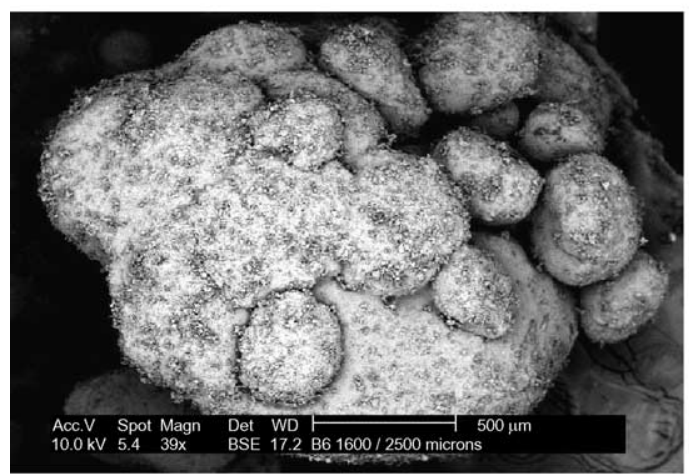

(b)

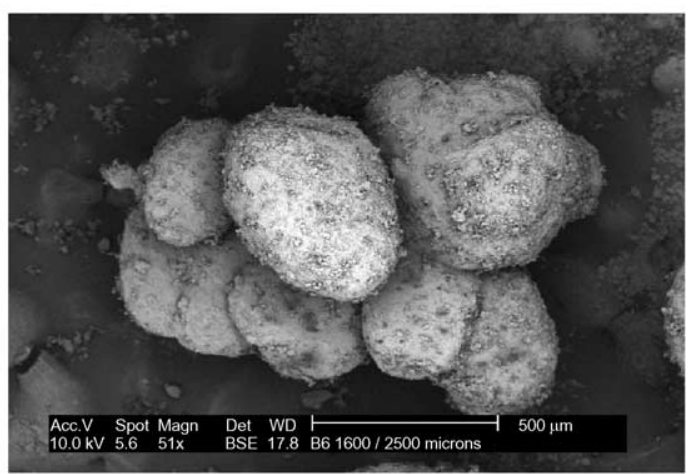

Fig. 6. (a-b) Extensive (Regime III), granules $(1600-2500 \mu \mathrm{m}), \mathrm{L} / \mathrm{S}=31.7 \%$, top $=19 \mathrm{~min}, N=500 \mathrm{rpm}$. 
Table 4

Granulation parameters - shear effect

\begin{tabular}{llllll}
\hline $\begin{array}{l}\text { Pulverisation } \\
\text { rate }(\mathrm{g} / \mathrm{h})\end{array}$ & $\begin{array}{l}\text { Impeller } \\
\text { speed }(\mathrm{rpm})\end{array}$ & $\begin{array}{l}\text { Powder } \\
\text { mass }(\mathrm{g})\end{array}$ & $\begin{array}{l}\text { Operating } \\
\text { time }(\mathrm{min})\end{array}$ & $\begin{array}{l}\text { Liquid } \\
\text { to solid } \\
\text { ratio } \\
(\mathrm{w} / \mathrm{w})\end{array}$ & $\begin{array}{l}\text { Chopper } \\
\text { presence }\end{array}$ \\
\hline 220 & $\begin{array}{l}100,500, \\
1000\end{array}$ & 200 & 19 & 31.7 & no \\
\hline
\end{tabular}

is not well dispersed on the powder bed. The result of the small-scale experiments can be used to interpret the nucleation stage in this Diosna granulation process. At an impeller speed of $100 \mathrm{rpm}$, the powder bed changes from being a moving bed to a well-mixed bed because the gravity force $\left(F_{\mathrm{g}}\right)$ becomes equal to the centrifugal force $\left(F_{\text {cen }}\right)$ :

$F_{\mathrm{g}}=m g$

$F_{\text {cen }}=m \frac{(\pi N D)}{(D / 2)}$

$N_{\mathrm{c}}=\left[\frac{g}{2 \pi D}\right]^{1 / 2}$

In this, $m$ is the mass, $g$ the acceleration due to gravity, $N$ the speed of rotation of the impeller, $D$ the diameter of the bowl and $N_{\mathrm{c}}$ the critical impeller speed. The powder bed moves in a chaotic, fluidised manner, and droplets of binder will fall onto a cloud of powder particles.

For the other impeller speeds (500 and $1000 \mathrm{rpm}$ ), almost all the powder is granulated $(\approx 90 \% \mathrm{w} / \mathrm{w})$. The mass median diameter is approximately the same $(d \approx 1.1 \mathrm{~mm}$. $)$, but the distribution is narrower in the case of a higher shear granulation. In addition, the presence of fine granules can be noted at $1000 \mathrm{rpm}$, which are absent at $500 \mathrm{rpm}$. This can be explained by the fact that the mechanism of granule breakage occurs when stress due to mechanical agitation is important.

The breakage of fine granules can be explained by an order of magnitude estimation of the pressure caused by the impact on a fine granule by the impeller. In order to calculate the impact pressure, the acceleration $(a)$ of the fine granule on impact can be estimated as:

$a=\frac{\Delta v}{\Delta t} \approx v_{\text {tip }} \frac{v_{\text {tip }}}{d_{\mathrm{p}}}$

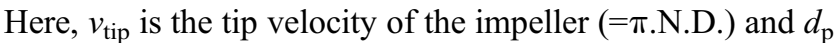
is the diameter of the fine granules. A better estimation of the acceleration could be obtained by using more rigorous mathematical models such as the distinct element methods $[14,15]$

\subsubsection{Influence of shear on porosity}

In order to characterise the granules, mercury porosimetry was performed on dry granules from three impeller speeds. Fig. 8 represents porosity versus granule diameter for each impeller speed.

The porosity becomes lower after intense mechanical action. It can be seen that the higher the shear, the less porous are the granules. This result clearly reveals the mechanism of densification. The lower is the impeller speed, the less the granules are stressed, and the less important is the mechanism of densification. Another important observation is that the granulation of powder with a given binding liquid results in the formation of granules of very different characteristics in terms of porosity, depending

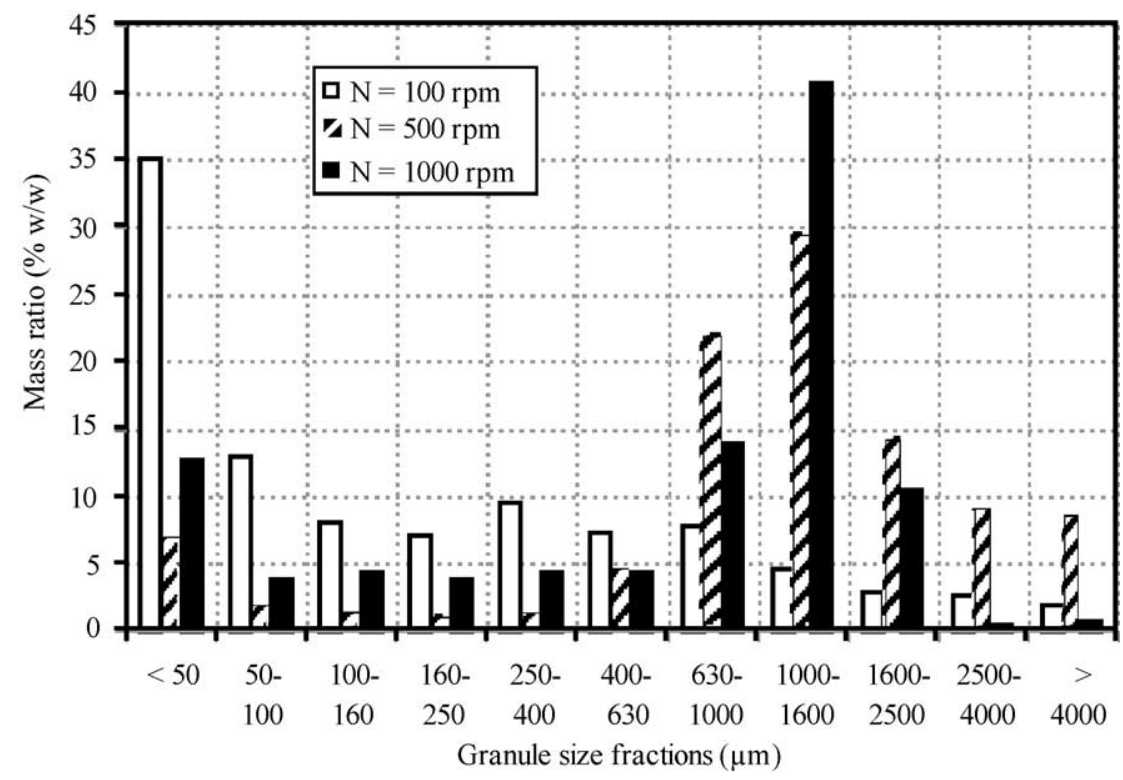

Fig. 7. Shear effect on granule size distribution, $\mathrm{L} / \mathrm{S}=31.7 \%(\mathrm{w} / \mathrm{w})$, top $=19 \mathrm{~min}$. 


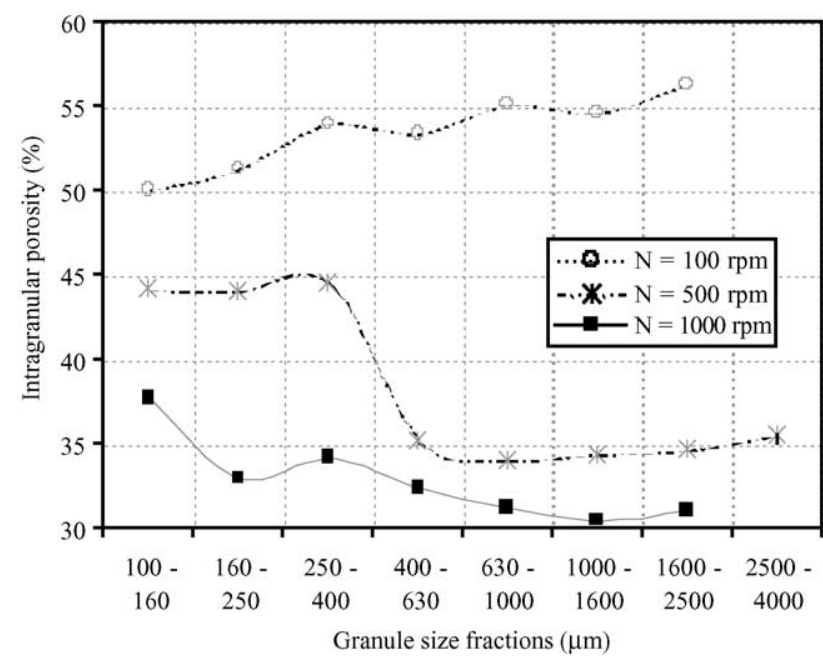

Fig. 8. Shear effect on intragranular porosity of granule size fractions, $\mathrm{L} / \mathrm{S}=31.7 \%(\mathrm{w} / \mathrm{w})$, top $=19 \mathrm{~min}$.

on operating conditions. It is found that granules with a given porosity can be obtained by changing impeller speed. Mechanical energy brought to the granulation system is as important as the physicochemical characteristics of the powder-binder pair. Furthermore, whatever the impeller speed, the granule properties depend on their size class.

\subsubsection{Influence of shear on friability}

Fig. 9 represents the friability index (percentage of broken granules after 200 revolutions in a special cell) versus granule diameter as a function of impeller speed. The higher the index, the more friable are the granules.
First of all, it can be seen that granules produced by a high impeller speed are less friable. The results described above lead us to expect this behaviour. Moreover, granules obtained by a high agitation are more homogeneous which is in accordance with the results on porosity.

Finally, by changing mixing conditions, we can obtain a wide range of granule hardness (friability index: 5-60\%). This result is very important for future compaction tests.

A further important remark is that it is not the least porous granules which have the lowest friability. This is probably due to growth mechanisms, which are different, depending on granule size.

\subsubsection{Influence of shear on binder content}

In the literature [16], mechanical properties (friability and hardness) are often related to the binder to solid ratio. The more binder used, the harder are the granules. The influence of binder content on the growth behaviour in granulation has been the subject of numerous recent papers [4,5]. Here, we determine the binder to solid ratio per size fraction of granules by thermogravimetry as described in earlier work [6]. Fig. 10 shows the mass binder content per size fraction for the three impeller speeds in comparison with the theoretical overall result $(5.7 \% \mathrm{w} / \mathrm{w})$. We observe that the composition of granules is heterogeneous in the case of the low impeller speed.

In addition, and in particular at $100 \mathrm{rpm}$, the friability (Fig. 9) is not directly linked to the binder content. For 500 and $1000 \mathrm{rpm}$, the binder content is practically constant and close to the theoretical value. This indicates that, on one hand, the binder is well dispersed on the powder bed and, on the other hand, there is no binder loss during granulation.

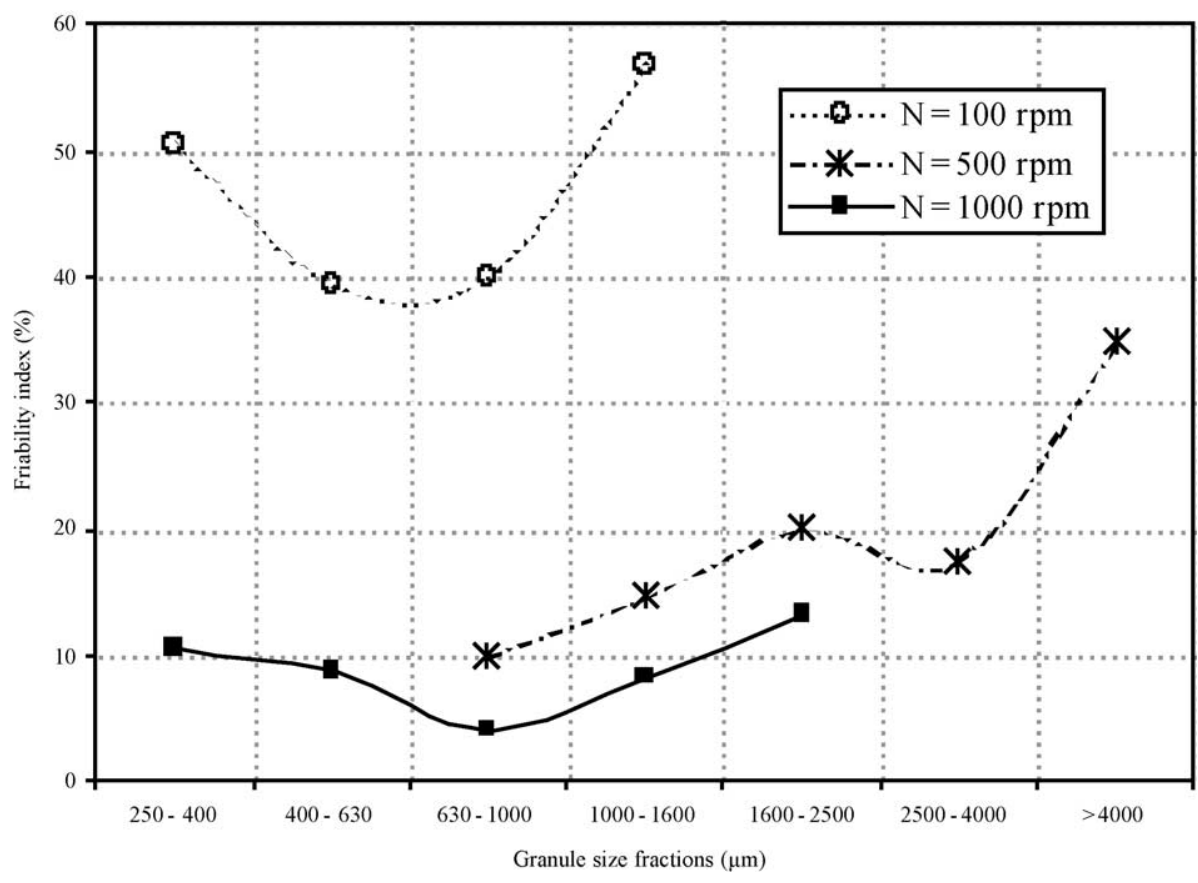

Fig. 9. Shear effect on friability of granule size fractions, $\mathrm{L} / \mathrm{S}=31.7 \%(\mathrm{w} / \mathrm{w})$, top $=19 \mathrm{~min}$. 


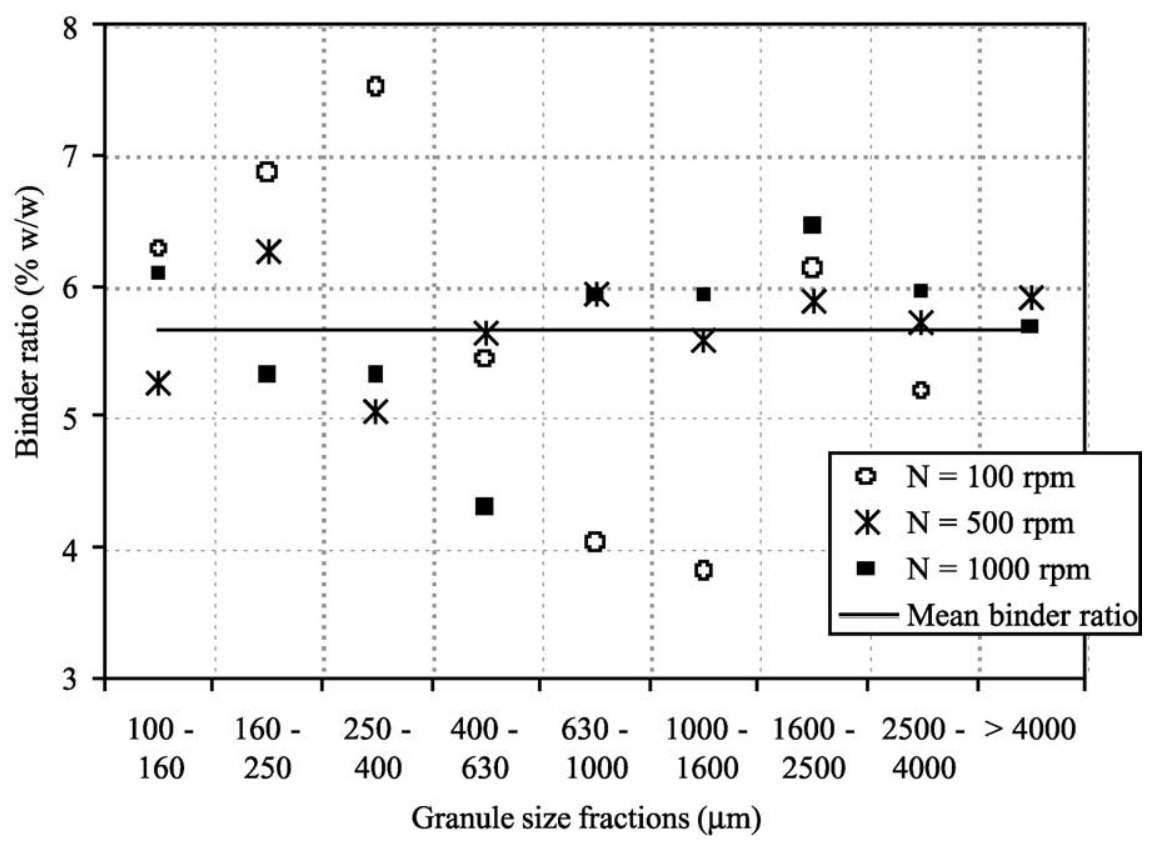

Fig. 10. Shear effect on binder content of granule size fractions, top $=19 \mathrm{~min}, \mathrm{~L} / \mathrm{S}=31.7 \%(\mathrm{w} / \mathrm{w})$.

\subsection{Comments and discussion}

It has been shown that the granules produced at 100 rpm are sub-optimal, i.e. wide size distribution, high porosity and friability and great variation in the binder contents. This can be explained, firstly, by the existence of a critical speed $N_{\mathrm{c}}$ (see Section 3.2.1) for optimal granulation and growth regimes. In granulation processes, two main growth regimes have been identified [17]: steady growth and induction type behaviour. Steady growth occurs when the deformability is high. The granules have a large contact area on collision with leads to a higher probability of coalescence. This results in a steady increase of the granule size. Induction type behaviour is observed in low-deformability systems. It is concluded that increasing the pore saturation, by increasing the binder content, decreases the induction time.

\subsection{Comparison with low-shear granulation (pan gran- ulator)}

In previous work [6], the granulation of the same binder/ solid couple was studied in a pan granulator. In this case of low energy mixing, the binder may not be homogeneously distributed over the granules. In a pan granulator, heterogeneity is a result of different methods of binder addition. Here, in the case of high-shear granulation, it is found that less liquid is required. For an optimal granulation in a low-shear granulator, the necessary liquid to solid ratio is about $36 \%$, whereas in a high-shear granulator, we need only $25-32 \%$.

In addition, granules obtained in a pan granulator are very different from those obtained in a high-shear granulator in terms of size distribution, porosity, friability and binder content. In the first case, we obtained a large size distribution and it was found very difficult to control granule size and since the characteristics of granules depend a lot on their size. The granules obtained in the pan granulator are less homogeneous.

Granules obtained in a high-shear granulator were found to be less porous: $50-60 \%$ for low-shear granulator, 30 $55 \%$ for high-shear mixer. Therefore, they are more friable, and the binding agent is less well dispersed due to the stress on granules. The lower the speed of agitation, the less the granules are stressed.

In addition, in the case of high-shear mixer, we can easily obtain granules with given characteristics by changing the mechanical energy brought to the granulation system. Highshear granulation is easier to control, whereas in pan granulator, granule characteristics cannot be varied much by changing the operating conditions.

\section{Conclusion}

The aim of the work presented here is to gain a better understanding of the effect of the impeller speed on granule properties in a high-shear granulator. The results of our study on wet granulation of a fine powder show the great importance of shear on granule growth and their final properties. The higher the impeller speed, the lower is the porosity and friability of the granules, and the narrower is the size distribution. It was noted that increasing shear does not induce more homogeneous granules. Granule properties depend on their size, whatever the impeller speed. As for low-shear granulation, friability is not directly linked with the binder ratio. 
In conclusion, the main result of this study is that granulation of a fine powder with a given binding liquid can lead to the formation of granules of very different characteristics in terms of size, porosity, friability and binder content, depending on the operating conditions used. Mechanical energy brought to the granulation system is as important as the physicochemical characteristics of the powder-binder pair.

Together with a granule size population balance, the future work will propose a "densification balance" based on porosity and density, a "dispersion balance" based on liquid distribution and a "composition balance" based on the binder/solid composition of granules.

\section{Acknowledgements}

The authors wish to thank J.F. Tranchant (Christian Dior) for his kind cooperation and support.

\section{References}

[1] P. Holm, O. Jungersen, T. Schaefer, H.G. Kristensen, Pharm. Ind. 45 (8) (1983) 806-811.

[2] A. Jaegerskou, P. Holm, T. Schaefer, H.G. Kristensen, Pharm. Ind. 46 (3) (1984) 310-314.

[3] L. Vialatte, "Mécanismes de granulation. Application à la granulation par agitation mécanique", $\mathrm{PhD}$ thesis, Université de Technologie de Compiègne, Février, 1998.

[4] P. Knight, T. Instone, J.M.K. Pearson, M. Hounslow, Powder Technol. 97 (1998) 246-257.

[5] A. Scott, M. Hounslow, T. Instone, Powder Technol. 113 (2000) $205-213$.

[6] F. Cordier, D. Oulahna, L. Galet, J.A. Dodds, Wet granulation and population control: a novel approach of population balance per binder balances, 2nd European Congress Of Chemical Engineering, France, 1999.

[7] B.J. Ennis, G.I. Tardos, R. Pfeffer, Powder Technol. 65 (1991) 257-272.

[8] W. Pietsh, Size Enlargement by Agglomeration, Wiley, Chichester, 1991.

[9] F. Hoornaert, P.A.L. Wauters, G.M.H. Meesters, S.E. Pratsinis, Powder Technol. 96 (1998) 116-128.

[10] B.C. Hancock, P. York, R.C. Rowe, Int. J. Pharm. 102 (1994) $167-176$.

[11] P. York, R.C. Rowe, Monitoring granulation size enlargement processes using mixer torque rheometry, First International Particle Technology Forum, Denver, USA, 1994.

[12] P. Stevens, L. Gypen, R. Jennen-Bartholomeussen, Farm. Tijdschr. Belg. 51 (1974) 150-155.

[13] C.E. Capes, Particle size enlargement, in: J.C. Williams, T. Allen (Eds.), Handbook of Powder Technology, vol. 1, Elsevier Scientific Publishing Co., Amsterdam, Oxford, New York, 1980, pp. 52-81.

[14] A.V. Popatov, C.S. Campbell, Powder Technol. 81 (1994) 207-216.

[15] C. Thornton, K.K. Yin, M.J. Adams, J. Phys., D, Appl. Phys. 29 (1996) 424-435.

[16] S.M. Iveson, J.D. Litster, B.J. Ennis, Powder Technol. 88 (1) (1996) $15-20$.

[17] S.M. Iveson, J.D. Litster, AIChE I. 44 (7) (1998) 1510-1518. 